\title{
És o avesso do avesso
}

\author{
WALTER BARELLI
}

$\mathrm{N}$

o S Ú LTIM os 25 anos, a cidade de São Paulo apresentou grandes transformações. N osso propósito, neste texto, a partir disso, é relacionar como as alterações ocorridas no emprego e no trabalho estão ligadas a essas mudanças na cidade.

U m dos fenômenos urbanos notáveis do século $X X$ foi a transformação da cidade de São Paulo em uma das maiores metrópoles mundiais. I niciou o século ainda como capital de um Estado essencialmente agrícola. Seu crescimento decorreu do sucesso da lavoura cafeeira, que permitiu investimentos diversos em infra-estrutura (ferrovias, hidroelétricas), em ciência e tecnologia (o I PT tem 104 anos), além de concentrar outros serviços auxiliares da comercialização do café (porto de Santos, bancos, armazéns gerais).

Baseada no trabalho assalariado, a lavoura cafeeira criou um mercado interno de consumo que se tornou a base de expansão da indústria. A crise de superprodução do café e os mecanismos de defesa adotados mantiveram o mercado existente e as guerras mundiais o reservaram para as indústrias locais. A política industrialista, advinda da revolução de 1930, mesmo quando grandes unidades e sedes de empresas, como CSN , Petrobrás, Eletrobrás, ficavam em outro Estado, favorecia São Paulo, quer no fornecimento de matéria- prima, quer na ampliação do seu mercado.

As chamadas economias externas, que a região oferecia, também atraíram os investimentos estrangeiros, em especial a partir do Plano de M etas do governo J uscelino Kubitschek.

A partir da segunda metade da década de 1950, cresce a área de influência da cidade, a chamada Grande São Paulo. N ela, os limites dos municípios são apenas divisões político-administrativas. A capital é referência para as cidades do entorno. As indústrias auxiliares vão procurando a localização mais apropriada para suas fábricas, em especial às margens das rodo vias radiais que alimentam São Paulo e são alimentadas por ela. Essas rodovias também visão a se tornar ser caminhos para a criação de novos centros, já mais distantes, mas que se referem a São Paulo, como Campinas, São José dos Campos, Santos, Sorocaba.

A existência, na região, de trabalhadores com experiência, foi um dos fatores que levou a essa concentração de investimentos. Será que as mesmas condições continuaram no final do século XX e começo do atual? É o desafio que a nos propomos neste estudo, tentando verificar, em especial, o que está acontecendo com o emprego e o trabalho na região. 
D urante 480 anos, a questão de emprego era inversa. Era conseguir braços. O s primeiros movimentos não são dignos de elogio: a vinda de degredados, a escravidão dos indígenas, o tráfico de negros. A expansão de São Paulo começa juntamente com a imigração européia, base tanto do novo mercado interno, como da indústria. $\mathrm{N}$ ão se restringiu somente aos europeus. Também vieram os asiáticos, principalmente os japoneses. No entanto, tão importante como os imigrantes estrangeiros foi o fenômeno migratório interno. Brasileiros de todos os Estados, em especial de M inas G erais e do N ordeste, para cá vieram, trabalharam e construíram esse mundo chamado São Paulo.

\section{R enasce o sindicalismo}

O primeiro movimento é o renascimento do sindicalismo brasileiro, que se dá a partir de 1978. A hegemonia do movimento sindical esteve, durante muito tempo, com o Rio de J aneiro e começou a se deslocar para São Paulo nos finais dos anos de 1950. Com as greves de 1978, é a vez de São Bernardo do Campo, na G rande São Paulo, assumir a liderança. O s sindicatos brasileiros que vinham sendo reprimidos pelo movimento militar, desde 1964, encontraram nova forma de expressão e ela transformou a vida política brasileira.

A década de 1980 foi de expressivas vitórias do movimento sindical. Grandes concentrações mostravam a representatividade dos sindicatos e a determinação dos trabalhadores. A força dos argumentos comprovando as perdas dos assalariados exigia correções, que tanto empresas como o Estado foram obrigados a fazer. As conquistas não foram somente de caráter trabalhista, como o fim das leis de arrocho salarial. Exigia-se democracia e ela foi conquistada, chegando-se a uma nova Constituição, em que os direitos dos trabalhadores foram reforçados.

A força política dos sindicatos levou à liberdade de organização e foram criadas, já sem interferência governamental, as centrais sindicais.

Cidade e região com maior quantidade de trabalhadores, São Paulo foi o cenário de muitas concentrações e movimentos do sindicalismo. N ão é à toa que as centrais sindicais nela têm suas sedes. Essa é uma característica importante a marcar a cidade - os trabal hadores a escolheram como capital de suas organizações. Não é só o capital que se concentrou na cidade. A mesma opção foi feita pelo trabalho organizado.

\section{M uda o trabalho - 0 avesso do emprego fácil}

E nquanto os trabalhadores passam a ser sujeitos coletivos com a força de seus movimentos, começam a ocorrer mudanças importantes - a chamada terceira revolução industrial ou era da informação. A microeletrônica modifica o processo de trabalho, aumentando a produtividade do trabalhador, ao eliminar ou diminuir os chamados tempos mortos, durante o processo produtivo. Acarreta a mudança do trabalho, seja no chão de fábrica, seja nos escritórios, seja nos bancos, seja na maioria das atividades em que entram ou possam entrar equipamentos. 
Paralelamente à introdução da microeletrônica, a organização do trabalho passa por transformações significativas, abandonando o padrão taylorista/ fordista da segunda revolução industrial. Busca-se o novo trabalhador, muito diferente do boçal pretendido por Taylor. Enquanto aquele deve seguir rigidamente as instruções e realizar somente suas tarefas explícitas e compartimentadas, este novo trabalhador deve ser polivalente, conhecer amplamente todo o processo de produção e assumir responsabilidades. O s níveis de supervisão são reduzidos ou eliminados, transferindo o mais das vezes para a máquina o controle do trabal hador.

Essas transformações levam à diminuição do número de trabalhadores necessários nas diversas atividades, quer nas indústrias, quer nos outros tipos de trabalho. São visíveis nos bancos, que reduziram o número de seus funcionários, chegando a transferir para os clientes vários tipos de operações. Já houve perto de um milhão de bancários. H oje são cerca de 380 mil. N a indústria automobilística, antes dessas transformações, cada trabalhador produzia em média 8,1 automóveis/ ano. Atualmente, produz 21,3 automóveis/ ano. Com isso, o número de trabalhadores no setor caiu cerca de $30 \%$

As comissões de fábrica e algumas direções sindicais começaram a conviver com essas mudanças, já na década de 1980, mas a inexistência do contrato coletivo de trabalho impediu uma ação acauteladora no que se refere ao número de empregos. Q uando se efetivam as mudanças tecnológicas e de processo, não há base para comparação sobre as perdas decorrentes em postos de trabalho. M as já podemos adiantar que uma parte do desemprego registrado na década de 1990 tem sua causa nessas transformações na forma de trabalhar.

\section{Fuga das empresas - 0 avesso do passado}

O mesmo processo que levou à concentração de atividades em São Paulo um dia mudou de sentido. Estar em São Paulo passou a representar um custo adicional que não existia em outras cidades. $D$ aí algumas empresas irem buscar em outras localidades uma situação que Ihes fosse mais conveniente. $\mathrm{O}$ utros governos estaduais e municipais criaram programas de atração de investimentos, 0 que se tornou um estímulo adicional para quem quisesse sair de São Paulo ou para desviar da região quem estivesse interessado em investir.

0 crescimento desordenado da cidade criou desestímulos. Além da dificuldade de se conseguir terrenos, o sistema viário é caótico, com congestionamentos constantes. A introdução de novos fluxos de materiais na idéia do tempo certo (just in time) é menos eficaz na cidade.

A fal ta de um sistema eficiente de transporte de massa e a distância cada vez maior entre o local de moradia e do trabalho levam para a empresa um trabalhador cansado, pelas horas perdidas no deslocamento, e muitas vezes atrasado ou ausente por problemas que ele e a empresa não podem controlar. A criação de um transporte próprio da empresa para fazer o deslocamento também significa um custo adicional que não resolve todos os problemas. 
A poluição, além de al gumas vezes comprometer a produção em áreas sensíveis, também se transforma em problema geral, quando os rodízios impedem a circulação de veículos em dias predeterminados.

O utros problemas se somam a esses, como as enchentes dos córregos e rios, os cuidados adicionais com a segurança, a iminência de racionamentos de água e energia elétrica, as exigências maiores da legislação local, como horário de funcionamento, controle de emissões, tratamento de efluentes. Para alguns, também importa ficar longe do movimento sindical mais organizado, que quase sempre representa pisos salariais maiores e mais demandas do conjunto de trabaIhadores. Tudo isso leva São Paulo a exportar postos de trabalho, ficando com o desemprego dos que não podem ou não querem acompanhar a mudança das empresas.

\section{São Paulo pode parar - 0 avesso do lema}

D epois de décadas de crescimento, com São Paulo acompanhando e impulsionando a economia do país, a década de 1980, com os problemas de pagamento da dívida, da falta de capitais para investimentos e da inflação renitente, reduz a taxa média anual de crescimento do PIB para 3\% C rescimento econômico menor acarreta menor criação de empregos e, pela primeira vez, esse fenômeno pode ser acompanhado.

O País e São Paulo passaram a ter estatísticas de emprego e desemprego, nessa década. A fonte dos nossos dados é a PED - Pesquisa de E mprego e D esemprego, do DIEESE e Fundação Seade, que é feita mensalmente, a partir de 1985.

O s primeiros anos dessa pesquisa mostram uma taxa de desemprego elevada, flutuando em torno de $9 \%$ É um período de incertezas para o empresariado, alimentadas pelos planos de ajuste que se sucederam a partir de 1986. Com momentos de expansão, nos meses que se seguiam aos Planos Cruzado, Bresser e Verão, e ante um movimento sindical fortalecido, a opção foi cortar nos salários e resguardar minimamente os empregos.

Apesar de os anos de 1980 serem chamados de década perdida, as condições de emprego e trabalho vão piorar nos anos de 1990, que sem dúvida afetaram mais o trabalhador. As mudanças econômicas continuam acontecendo. De início, há uma ruptura abrupta de nossa economia, expondo empresas anteriormente protegidas a uma concorrência para a qual não tinham se preparado. A pequena recuperação iniciada em 1993 é seguida, em julho de 1994, de um bemsucedido programa de estabilização ancorado em uma política cambial de valorização da moeda nacional. No entanto, antes de completar um ano de Plano Real, para que se pudesse manter o câmbio valorizado, são adotadas medidas restritivas na área financeira, com limitações ao crédito, entre elas a elevação das taxas de juros.

Essa dura política monetária continua até hoje, apesar da adoção do câmbio flexível em 1998, principal causa do baixo crescimento econômico. N a déca- 
da de 1990, o PIB cresceu menos de $2 \%$ ao ano, muito próximo da taxa de crescimento da População E conomicamente Ativa, ou seja, a economia não conseguiu incorporar os novos contingentes populacionais que chegavam ao mercado de trabalho.

É a década do desemprego. Começa com 10\% da PEA desempregada em 1990. E m 1992, a taxa de desemprego já é de 15,2\% H á uma pequena diminuição até 1995, caindo para 13,2\%. A seguir cresce, variando de $17,6 \%$ a 19,3\% de 1998 a 2002, ou seja, o novo milênio também começa com altas taxas de desocupação. E sses números referem-se ao desemprego na Grande São Paulo. N a C apital, a taxa é algo menor (em torno de 1\%), mas não dá para circunscrever o problema aos limites da cidade. São Paulo passa a ser uma cidade onde a oportunidade de emprego para todos não mais se realiza.

$\mathrm{N}$ ão é fenômeno unicamente paulista ou brasileiro. As mudanças no trabaIho ou o crescimento do desemprego são encontrados em outros locais também. $M$ as São Paulo resume praticamente todas as características do que aconteceu com o trabalho e o trabalhador e também permite antever o que está por vir. É nosso ponto de observação para conhecermos mais sobre o que está acontecendo com a população nestes últimos anos.

\section{Mudança no trabalho - A mulher}

A transformação mais profunda do mercado de trabalho é a presença sempre maior da mulher. Temos aqui uma transformação estrutural e cultural. Tabus antigos são derrubados e o trabalho feminino ganha espaço, não só por razões econômicas, como na primeira revolução industrial, mas também pelo novo papel conquistado pelas mulheres na sociedade. Já foi mera complementação da renda da família, agora é também realização pessoal. E mbora a cidade não tenha se preparado para isso, haja vista a inexistência de creches para to das as crianças, a mulher está pronta para o trabalho fora de casa e reorganiza seus interesses e sua vida familiar para ter sua própria fonte de renda e de satisfação.

A PED - Pesquisa de Emprego e D esemprego - nos ajuda a acompanhar a marcha dessa inserção. Em 1985, entre a população ocupada, $61,3 \%$ eram homens e $36,9 \%$ mulheres. Em 2001, os homens constituíam 56,8\% dos ocupadose as mulheres já eram $43,2 \%$. Se olharmos os desempregados, a outra parte constitutiva da População Economicamente Ativa, em 1985, 51,2\% eram homens e 48,8\% mulheres, passando em 2001 para 46,7\% de homens e 53,3\% de mulheres. 0 maior número de desempregadas revela mais que a existência de discriminação no mercado de trabalho. Confirma, pelo contrário, uma pressão para que mais mulheres tenham ocupação.

Tratando-se de contingentes que disputam o mesmo mercado, vê-se que, ou se tem um crescimento expressivo de postos de trabalho, hipótese irreal izável em uma economia de baixo crescimento, ou a mulher e o homem passarão a disputar as poucas vagas abertas. É conhecido o papel do exército de desempre- 
gados em relação às condições de trabalho e salário dos trabalhadores. Q uem concordar com rebaixamentos pode ter acesso imediato ao emprego. U m estudo do DIEESE mostra que em 1999, 43,3\% das mulheres estavam em postos de trabalho vulneráveis para 31,3\% de homens na mesma situação.

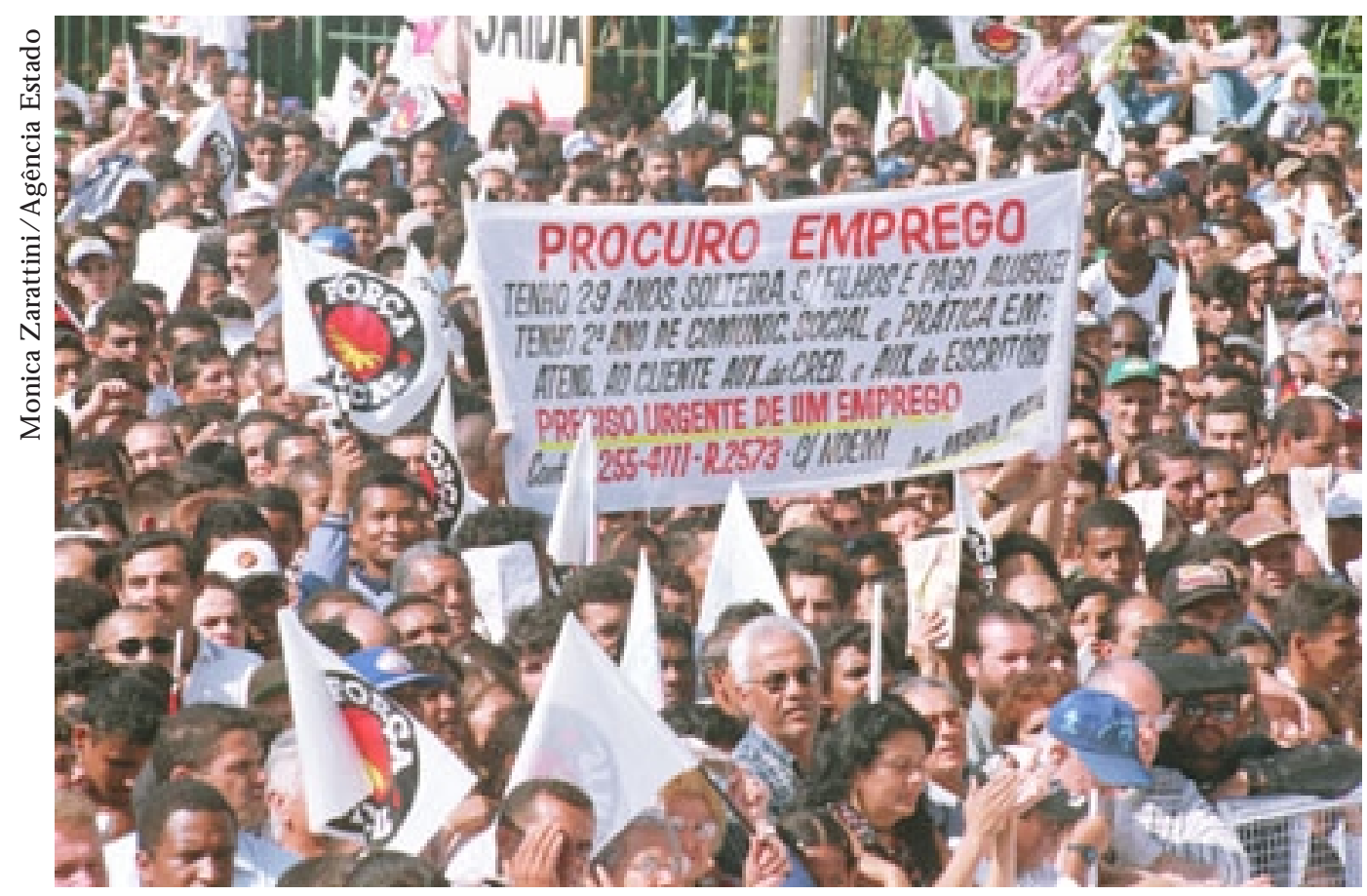

M anifestação contra o desemprego realizada no Sambódromo, em São Paulo.

Por PEA - População E conomicamente A tiva - entende-se o conjunto de pessoas voltadas para o trabal ho, ou seja, a soma de ocupados e desempregados. C ontrapõe-se à PIA - População em I dade A tiva -, que é o conjunto de pessoas em idade de trabalho (no Brasil, maiores de dez anos para efeito estatístico). A PIA difere da PEA pelo conjunto de pessoas que têm idade de trabalho, mas não estão voltadas para o trabalho, em sentido econômico (estudantes, donas de casa, aposentados, encarcerados e semelhantes). H oje, a PEA vem aumentando não apenas pelo crescimento vegetativo da população, mas também porque cada vez maior número de mulheres passa a integrar o mercado de trabalho.

A conseqüência é que a economia é infensa a esse fenômeno. E le pode ser útil para rebaixar salários ou condições gerais de trabalho. C omo se pode substituir homens por mulheres, os que não forem colocados vão engrossar as fileiras dos desempregados. 0 que antes foi resolvido parcialmente com as mulheres ficando em atividades caseiras, a família tendo no papel reservado às mulheres uma forma de "poupar" salário, pois elas proviam a educação, a saúde e o bem-estar possível para cada lar, muda totalmente de figura. A mulher encara a dupla função - o trabalho fora e o de casa, às vezes com a participação do homem - mas 
não tem condições de ter todo o tempo que antes possuía para cuidar dos filhos e da casa. E ssas transformações mudam as condições de vida na cidade, em especial para as crianças e adolescentes e para os velhos, que costumavam ter maior assistência no modo anterior de organização familiar.

Em outros países, o fenômeno da maior presença da mulher no mercado de trabal ho aconteceu na época de expansão de suas economias. Aqui ele é intenso em uma fase de baixo crescimento, o que realça os mencionados aspectos perversos.

\section{M udança no trabalho - Os jovens}

L egalmente, o trabalho só é permitido a partir dos dezesseis anos. Como a realidade é diferente, as estatísticas de emprego têm como corte inicial a idade de dez anos. Ainda assim, é uma convenção que não abrange toda a realidade, pois nas cidades grandes vêem-se crianças com menos de dez anos vendendo balas ou quinquilharias nas esquinas movimentadas. É nas faixas de idades menores que se encontram as maiores taxas de desemprego: 48,3\% na faixa etária de dez a catorze anos; $47 \%$ na de quinze a dezessete anos e $25,2 \%$, na faixa de dezoito a vinte e quatro anos, dados esses referentes a 2001.

Esses números são indicações de pobreza. Pois crianças trabalhando e a resposta dos pais ao entrevistador da PED, afirmando que seus filhos menores estão procurando emprego, até antes da idade legal para o trabalho, são atestados do quadro de necessidades enfrentadas por eles. 0 utra face da moeda é o trabalho, substituindo a escola, o lazer, a cultura ou o esporte. 0 tempo do jovem tem de ser preenchido e a pressão é que seja pelo trabalho, qualquer trabaIho, no espectro que vai da legalidade à ilegalidade.

Vivendo essa situação, o jovem e sua família vão adotando novas atitudes. E mbora permaneça o trabal ho precoce, mesmo antes da idade legal, começa a se fortalecer a idéia de que educação é condição necessária para que se tenha emprego. Aí valem os sacrifícios para que os estudos não sejam interrompidos, investimento que está sendo feito no futuro dessa geração. Q uando se nota que a juventude européia adia ao máximo a entrada no mercado de trabalho - porque também lá não há emprego para todos - o mesmo movimento já se esboça em São Paulo. N ão se abandona, com tanta facilidade, a escola porque se precisa trabalhar. $\mathrm{H}$ á consciência de que não há trabalho. Até mesmo uma parcela daqueles que desistiram dos estudos no passado, anseiam por uma oportunidade para voltar à escola.

O snúmeros ajudam no conhecimento dessa nova face do trabalho de crianças e jovens. U ma notícia alvissareira é a queda no número de ocupados na faixa de dez a catorze anos: cai de 2\%em 1985 para 0,8\%, em 2001. O u seja, está diminuindo o registro de trabalho ilegal em São Paulo. 0 mesmo acontece na faixa seguinte de quinze a dezessete anos. 0 número de ocupados cai de 5,8\%, em 1985, para 3,2\%, em 2001. Aqui também devemos nos referir à discriminação contra 0 
emprego dos jovens em idade de serviço militar. A lei que os protege voltou-se contra eles, sendo prática de muitas empresas não contratar jovens que possam vir a ser convocados.

O utra informação nos vem dos dados referentes a jovens procurando emprego. N a primeira faixa, de dez a catorze anos, havia $10 \%$ de desempregados em 1985 e somente $3,3 \%$ em 2001 . N a segunda faixa, de quinze a dezessete anos, havia $17,6 \%$ de desempregados em 1985, caindo para 13,5\% em 2001. Se diminui a proporção de jovens ocupados e desempregados, a conclusão é que está crescendo a inatividade. N umericamente, na faixa de quinze a dezessete anos, os inativos que eram 36,2\%em 1985 passam para 52,8\% em 2001. É uma tendência diferente daquela das mulheres que saíram da inatividade para pressionar por vagas no mercado de trabalho. O s jovens paulistas estão em movimento contrário. D iminuem a pressão por empregos. A permanência por mais tempo na escola explica parte dessa condição de inatividade. H á outras explicações também. No caso das adolescentes, muitas estão substituindo as mães que trabalham, cuidando dos irmãos menores e de outros afazeres domésticos. 0 adiamento do ingresso no mercado de trabalho pelos jovens é uma tendência que deve se acentuar, desde que a cidade dê a eles e a suas famílias condições de se sustentarem, durante esse período de investimento no futuro.

\section{M udança no trabalho - 0 envelhecimento}

V ista a situação dos jovens, é importante verificar também o que está acontecendo com quem tem mais de quarenta anos. Do mesmo modo que se nota um envelhecimento da população, também no mercado de trabalho cresce a participação de quem tem mais de quarenta anos. Essa faixa representava $25 \%$ dos ocupados em 1985, aumentando sua participação para 34,3\% em 2001 . Em épocas de crise, as empresas têm suas regras pró prias de dispensa. U ma delas é não perder as pessoas mais capacitadas do seu quadro. O s dados de ocupação parecem indicar isso.

A lógica é diferente, quando se trata de contratar um novo empregado. Os mais idosos têm mais dificuldades. I sso aparece claramente quando verificamos o percentual de desempregados com quarenta anose mais. E m 1985, correspondia a $11 \%$ dos desempregados. Em 2001, era de $20,4 \%$, tornando esse grupo aquele que teve maior crescimento no número relativo de sem emprego.

Perder o emprego para o idoso passa a ser trágico, se ele ainda não contar tempo para a aposentadoria. É uma situação que precisa ser acompanhada de perto, pois a sociedade não está preparada para ela.

\section{A Precarização no trabalho}

As características já analisadas permitem verificar mudanças no emprego em São Paulo. Q uase todas mostram o avesso do que foi a situação do trabalhador na Capital. O termo "precarização do trabalho" incorpora a noção de que as condições foram melhores e decaíram, na última década. 
A principal forma de expressão dessa queda de qualidade é dada pela diminuição dos assalariados com vínculos formais de trabal ho e o crescimento da chamada informalidade. Entre os ocupados, cai o percentual dos que trabalham com proteção legal: em 1985, 51,9\% tinham carteira assinada e em 2001, somente 40,8\% E m decorrência, aumentou o número de trabal hadores na informalidade: em 1985, 8,2\% não eram registrados, passando para 14,2\%, em 2001.

$\mathrm{N}$ ão ter carteira assinada deixa o trabalhador fora da proteção da lei, no que se refere aos direitos trabalhistas e previdenciários. O Ihando para o futuro, esse trabalhador não só tem menos benefícios no dia de hoje, como ele e sua família não terão proteção alguma na velhice, ou se a tiverem, será às custas das próximas gerações. O s que estão nesta situação também têm salários menores do que os trabalhadores com registro. Embora seu salário atual seja um pouco maior do que em 1985, ele é ainda somente $62 \%$ do que recebe 0 trabalhador com carteira.

O utra faceta da precarização é o crescimento do número de autônomos. $\mathrm{N}$ ão havendo emprego, exercer uma atividade por conta própria é uma saída, com os riscos assumidos pelo próprio trabalhador. O s autônomos eram 15,1\% dos ocupados em 1985. Passaram para 21,2\%, em 2001, crescendo mais o número dos que trabalham para o público, do que o dos que trabalham para as empresas.

O s que trabal ham para o público, em grande parte camelôs e ambulantes, estão condicionados à renda de sua potencial freguesia. Como nem to dos conseguem regularizar sua situação, estão sujeitos a perder suas mercadorias ou a ser coniventes com os fiscais corruptos.

O s que trabalham para empresas submetem-se a outra dinâmica. A sua autonomia nem sempre é total. A empresa contratante é quem determina preços e condições, que nem sempre podem ser alteradas. Além disso, no processo de terceirização, muitas empresas despediram trabalhadores, voltando a contratálos na forma de autônomos. E sse processo transfere para esses agora "terceirizados" as perdas por queda na produção ou nas vendas. Também são eles que passam a se responsabilizar pelos encargos so ciais da sua própria previdência, reduzindo 0 custo para a empresa contratante.

O utra violência contra os direitos dos trabalhadores é a utilização da contratação por meio de simulacros de cooperativas, muitas montadas pelas próprias empresas. Chamo a atenção de que as cooperativas têm sido uma saída coletiva para muitos que não encontram emprego assalariado, quer entre a população de baixa renda, quer entre comunidades de profissionais, dispensados por grandes empresas. Essa forma de organização tem aumentado na região, com apoio governamental e sindical. É uma estratégia de ocupação através do modelo cooperativo, a exemplo do que existe em muitos países. 0 que se combate é a utilização do nome de cooperativa, para contratar trabal hadores sem obedecer à legislação do trabalho, aproveitando-se da ignorância de muitos que precisam trabal har e das deficiências de fiscalização. 
Completando o quadro do trabalho precário, vamos encontrar ainda uma parcela de $10 \%$ da população trabal hando no emprego doméstico ou como trabalhadores familiares sem remuneração salarial. Esse percentual cresceu muito pouco no período $(0,2 \%)$.

Em grandes números, considerando como trabalhador vulnerável o sem carteira assinada, o autônomo que presta serviços ao público, o empregado doméstico e o trabal hador familiar sem salário, a região contava em 2001 com 37,2\% dos ocupados nessa situação. Em 1985, pelo mesmo critério, o trabalho precário representava $26,6 \%$ dos ocupados. I nvertendo-se, os empregos regulares representavam 73,4\%, em 1985, caindo para $62,8 \%$ em 2001. Essa é uma medida da ordem de grandeza do trabalho precário na Capital. É só uma aproximação, pois não consideramos os trabalhadores registrados, com baixos salários, nem os microempresários, cujos negócios mal permitem a subsistência, nem autônomos que fornecem para empresas, em dificuldades para manter suas fontes de trabalho.

\section{Terciário - Ainda o avesso}

"M aior centro industrial da América Latina" foi um dos motes ufanistas que caracterizou São Paulo. H oje, quase sem chaminés na Capital, a indústria ainda encontra local nos municípios vizinhos. 0 emprego industrial minguou. Em 1985, ainda era responsável por 32,1\% das ocupações. Em 2001, representa menos de $20 \%$ dos empregos (19,9\%). M esmo a construção civil, chamada de porta de entrada para o emprego, perdeu expressão.

Já mostramos o impacto das novas tecnologias e das transferências das empresas para outras regiões. R esta ver como os demais setores se comportaram no período.

O setor de serviços transformou-se no principal empregador. 0 aumento do emprego no setor quase compensou as perdas de empregos industriais. Em 1985, já tinham 41,7\% dos empregos; em 2001, ficavam com mais de metade dos ocupados (52,3\%). Esta comparação numérica não é acompanhada pela qualidade do emprego em serviços. Em média, a indústria paga mais e as condições de trabalho costumam ser melhores.

A exemplo da indústria, onde é possível separar indústrias dinâmicas e indústrias tradicionais, estas normal mente com condições de remuneração e trabaIho piores do que aquelas, no setor de serviços, o emprego cresceu principalmente na área de manutenção e oficinas, e nas áreas de serviços especializados, na saúde e nas novas demandas da economia global. Também aqui as condições de trabalho diferem. As atividades mais modernas, mais especializadas e mais inseridas na globalização oferecem condições melhores que as oficinas e serviços de reparação.

O utras atividades do terciário não foram desempregadoras, nem grandemente empregadoras: o comércio aumentou seu contingente em $2 \%$ no período e os serviços domésticos também tiveram um pequeno crescimento de $1,5 \%$ 
Estão aqui delineadas duas tendências para o futuro do emprego, na região. A primeira que aponta para a precarização do trabalho, representada no crescimento das oficinas e das atividades de manutenção e conservação. É uma grande área de emprego, em geral de baixos salários relativos e de fácil reposição do pessoal. Q uando se trata de serviços de caráter pessoal, seu crescimento depende da renda dos usuários, daí não poder ser considerado um setor propulsor do desenvolvimento. A segunda é a promessa de retomada das antigas glórias da Capital. Em uma economia globalizada, há funções especializadas que necessitam de centros irradiadores. As grandes empresas globalizadas precisam de pólos bem supridos de profissionais qualificados, com infra-estrutura dotada de sistemas de comunicações modernos, com redes de fibras óticas e domínio de altas tecnologias de informação. A América Latina precisa de uma cidade com essa função. Buenos Aires, Rio de J aneiro, Santiago e São Paulo concorrem para ser essa capital. Algumas das grandes empresas já fizeram sua escolha por São Paulo, pois a cidade tem uma vocação cosmopolita. Se afirmar essa vocação, marcará também a saída escolhida para o emprego. Realizará a proeza de iniciar um século como pólo da economia agro-exportadora, transformar-se em pólo industrial e viver um novo século como centro de serviços globais.

\section{Políticas públicas de emprego}

A principal conclusão que podemos tirar desta breve história do emprego recente em São Paulo é que o movimento populacional guarda pouca relação com a atividade econômica. Sempre se deu resposta às demandas de emprego, mesmo que se tratasse de atendê-las com as migrações. Foi possível construir uma capital como São Paulo que atrai e reproduz a força de trabalho para as necessidades da economia. 0 avesso, a economia responder às necessidades da população, não é promessa realizável em época de crise. As duas últimas décadas, em especial a de 1990, mostram que a cidade deixa de ser a M eca do emprego e acelera o passo para se igualar às populosas e pobres capitais asiáticas.

Estamos vivendo uma fase do crescimento sem emprego, no dizer de Eric H obsbawm. Poderíamos ser ainda mais cruéis, chamando de época do crescimento com desemprego, o que está sendo possível, na indústria, por meio da introdução da microeletrônica.

$\mathrm{H}$ á um desencontro entre a dinâmica da economia e a dinâmica da população. O s malthusianos diziam que haveria descompasso entre o crescimento da população e a produção de alimentos. 0 que se vive hoje é a falta de emprego para todos. O s projetos existentes propõem mais desemprego para resolver os problemas fiscais dos E stad os e das empresas. Conseguido isto, apregoam, o crescimento voltará e, quiçá, com ele haverá mais empregos.

$\mathrm{N}$ ão tendo para quem apelar, a população vai engendrando seus mecanismos de sobrevivência. Se a mãe precisa trabalhar, os filhos maiores são convocados para as tarefas do lar, em especial o cuidado das crianças. Se desaparece 0 
emprego do chefe de família, a mulher procura na área de serviços a maneira de a família ter o pão de cada dia. As pesquisas de emprego não conseguem capturar esses novos arranjos familiares. 0 termo exclusão é cada vez mais utilizado para definir essa nova realidade. Indo fundo no seu significado, mostra que esta sociedade não é para todos. E o trabalho, que era a forma de socializar pessoas, produção e renda, já não é mais o elo de integração.

Faltando o trabalho, a pessoa entra em uma espiral de perdas (Paugam). Perde de início a renda que a torna consumidora. Perde o convívio com os companheiros de trabalho. Se o desemprego se prolonga, começa a ter dificuldades com os mais próximos e com a pró pria família. A sua auto-estima é afetada. Passa a crer que o desemprego é questão pessoal, ele que não tem mais vez na sociedade. É o horror econômico (Forrester), que para muitos é mau conselheiro.

$\mathrm{O}$ rompimento dessa espiral vem com a reinvenção do trabalho. $\mathrm{H}$ á iniciativas, nesta direção, como o empreendedorismo, o trabalho voluntário e até o modelo paulista de Frentes de Trabalho.

Face à dificuldade de se obter um trabalho assalariado, várias iniciativas vêm surgindo - a opção do trabalho por conta própria ou a criação de uma pequena empresa. 0 crescimento do número de autônomos mostra a situação atual. Digna de nota é a iniciativa da formação de associações ou cooperativas populares, que unem desempregados que usam seus conhecimentos para conseguir uma pequena renda. É o empreendedorismo, indo contra a corrente.

O trabalho voluntário ou o chamado terceiro setor é outra oportunidade. Principalmente os jovens encontram no voluntariado ou nos estágios em O N Gs sua maneira al egre de participar. M uitos adquirem conhecimentos que passam a Ihes ser úteis, como a reciclagem de materiais e muitos organizam esse e outros trabalhos na comunidade.

As F rentes de Trabalho, no modelo paulista, dão a oportunidade para pessoas desempregadas de longa duração voltarem a atividades simples, de limpeza, pintura, pequenos consertos. São serviços prestados em escolas, hospitais, delegacias, parques e outras entidades públicas, que, ao valorizarem o trabalho, rompem a já citada espiral de perdas. Transforma-se em espiral de ganhos: ele ganha amigos, ganha o respeito da família e dos que convivem com ele no serviço, ganha principalmente a certeza de que não é uma sua hipotética incapacidade pessoal que o levou ao desemprego.

$\mathrm{H}$ á, também, iniciativas para atender o mercado de trabal ho existente. Ele vem aumentando os requisitos no recrutamento de pessoal, exigindo dos candidatos sempre mais escolaridade ou conhecimentos específicos. U ma parte das famílias e dos jovens já notou isso e não abandona os estudos com facilidade. Secundando as famílias, o poder público vem também investindo em educação, embora ainda falte muito a ser feito, em especial no que tange à qualidade.

$M$ as o caminho para aumentar as oportunidades de trabalho não se restringe às iniciativas das pessoas e das famílias ou só às já existentes do poder público. 
A cidade também tem a responsabilidade de propor ações nessa direção. São Paulo não esgotou suas possibilidades de desenvolvimento. D a própria crise atual pode sair o planejamento estratégico para o futuro.

D eixando de ser centro industrial, a capital está consagrada como centro de serviços. Ganhou essa condição da mesma maneira que ganhou a indústria no passado, por reunir as melhores condições tanto de infra-estrutura, como de recursos humanos, de mercado.

Para que haja empregos e bons empregos, esse é o caminho. Continuar investindo na infra-estrutura da região, formar os melhores quadros para as atividades de ciência, tecnologia e administração de projetos globais e ter iniciativas que façam o mercado local sempre crescer.

A pesar dos últimos anos de desemprego e precarização do trabalho, é possível sonhar com uma região metropolitana novamente impulsionadora do crescimento e do emprego. Ao mesmo tempo, são necessárias políticas públicas que, ao menos, amenizem os sofrimentos do desemprego que nos infelicita.

Walter Barelli é professor do Instituto de Economia da U nicamp. Foi ministro do Trabalho e secretário de Emprego e Relações de Trabalho do Estado de São Paulo. 